\title{
Commentary: A New Model for Chronic Care to Improve Patient's Skill
}

\author{
Patrick Dunn ${ }^{1,2 *}$, Scott Conard ${ }^{3}$ \\ 'Walden University, Minneapolis, MN, USA \\ ${ }^{2}$ American Heart Association, Dallas, TX, USA \\ ${ }^{3}$ Converging Health, Dallas, TX, USA
}

Article Info

\section{Article Notes}

Received: June 23, 2018

Accepted: July 19, 2018

\section{${ }^{*}$ Correspondence:}

Patrick Dunn, Ph.D, American Heart Association, 4137

Broken Bend, Keller, TX 76244, USA;

Email: pat.dunn@heart.org.

(c) 2018 Dunn P. This article is distributed under the terms of the Creative Commons Attribution 4.0 International License.
More effective treatment and increased survival from acute cardiometabolic conditions, such as heart attack and stroke, and an aging population has resulted in more people living with chronic conditions, such as coronary artery disease, heart failure, hypertension, high cholesterol, diabetes, and obesity ${ }^{1}$. With increased incentives to focus on the long-term outcomes of patients, we believe that there is an even greater need for more effective models for chronic care, both in research and in clinical practice ${ }^{2}$. Current approaches for increasing patient involvement range from low tech and low touch to high tech and high touch interventions that are delivered inconsistently and ineffectively. In cardiovascular disease and diabetes these approaches include formal and informal educational methods, print and digital media, apps and wearables that track activity blood pressure, weight, and glucose, and disease management programs such as cardiac rehabilitation and diabetes self-management programs ${ }^{3}$. Ultimately, high impact models are challenging to deliver in a clinical setting due to operational, resource, and reimbursement challenges.

In working together, we have created multiple programs that have been delivered at medical offices and corporations $\mathrm{s}^{4,5}$. On this journey there have been many times where people increased their knowledge and self-management skills, engaged in effective decision making and action, and improved their health significantly. Others became very health literate, in fact some to the point they could teach other patients the material, and yet they did not engage in improving their own health. After studying individuals with cardiovascular disease and diabetes, it became evident that being knowledgeable about their health was not enough. Chronic conditions, such as cardiovascular disease and diabetes require a high level of patient involvement, including taking medications and following nutrition and physical activity plans ${ }^{6,7}$. In addition, the challenge of addressing health literacy in chronic disease includes the lack of symptoms, or a lack of awareness of how symptoms are related to the condition, and thus the lack of urgency or continual reminding to remain engaged and active in managing the condition. This "I feel fine" syndrome reduces anxiety and the focus on treating the condition, resulting in non-adherence; in the case of asthma or COPD worsening of symptoms, and in the case of hypertension and elevated cholesterol advancement of the disease without additional symptoms. The challenge is in having the patient acquire an understanding of their 
situation that results in them taking positive lifestyle and medical condition management changes, accessing the healthcare system more effectively, and communicating more effectively with their healthcare team, resulting in better health outcomes.

Breakthroughs in scientific research are limited by the lack of engagement on the part of the patients. New technologies have been developed to make it easier for patients engage to manage their health and communicate with their healthcare team but will not make an impact on health outcomes at the current rate of adoption. While it is challenging to engage many patients as active participants in their care, this also represents an enormous opportunity to improve how healthcare is delivered.

Recently, the American Heart Association published a scientific statement on health literacy in cardiovascular disease $^{8}$. In the further exploration we have found that in addition to understanding how to manage their health, health literacy also includes the ability to calculate numbers (numeracy), navigate the healthcare system, communicate with healthcare professionals and care givers, and make good, well informed decisions ${ }^{9,10}$. Health literacy, therefore, involves more than simply communicating at a $5^{\text {th }}$ grade reading level, it requires building the knowledge and skills of the patient to meet the demands and complexity of the condition ${ }^{11}$. In fact, there is a pathway from health literacy to health outcomes, including achievement of treatment goals, reduced hospitalizations, and $\operatorname{cost}^{8,12,13}$. Also, critical and functional skills, such as numeracy, navigation, communication, and decision making have the potential to improve patient outcomes ${ }^{14-19}$.

\section{A New Model for Chronic Care}

We have, therefore, developed a new model for chronic care management that is focused on functional and critical health literacy skills (Figure 1). These skills allow the patient to better understand their condition and how to manage it and provide actionable steps to manage their health. These skills go beyond knowledge and comprehension to actionable skills that can help the patient apply this knowledge, including functional and critical health literacy skills ${ }^{20}$. These skills are not new nor are they unique to health literacy ${ }^{21}$. They do, however, appear to build from understanding the concept (knowledge and comprehension) to understanding the numbers associated with the condition (numeracy) to knowing how to access the healthcare system (navigation), to being able to communicate effectively with healthcare providers and care givers to ultimately making good, well informed decisions. This model applies not only to patients with low health literacy skills, but to all patients with chronic conditions, such as cardiovascular disease and diabetes.

While knowledge alone may not result in better health, it forms the foundation that will lead to more effective functional skills, such as numeracy and navigation, and critical skills, such as communication and decision making. The key is to present the information in manner that is relevant to the building higher levels skills. For example, while the patient may not need to fully understand the mechanism of action of their medications, they do need to understand which side effects they should be able to recognize side effects, and what to do if they appear. Example of knowledge and skills in each domain are presented in Table 1.

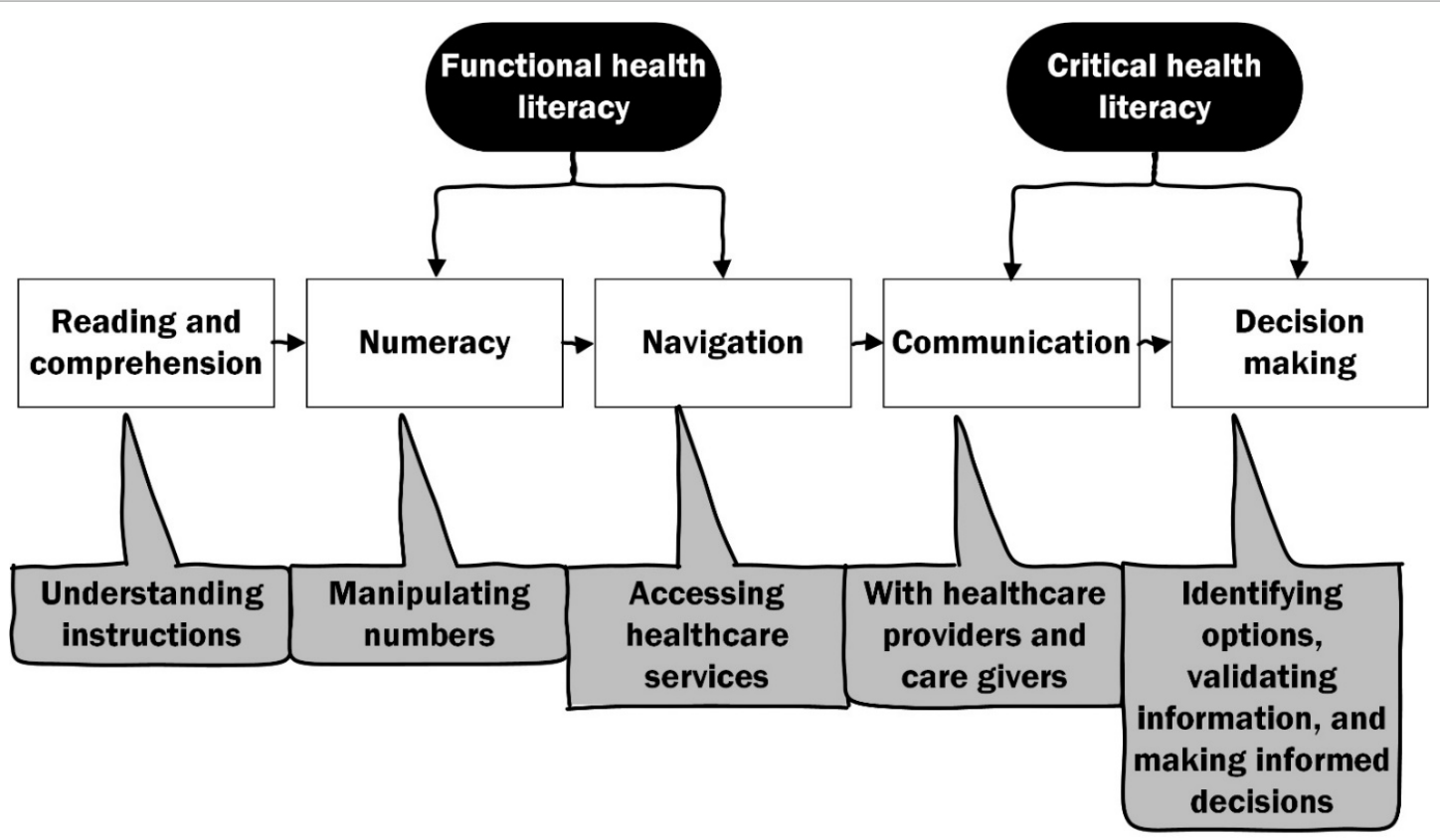

Figure 1: Progression of health literacy skills in chronic disease 
Table 1. Examples of critical and functional health literacy skills for patients with cardiovascular disease and diabetes

\begin{tabular}{|c|c|}
\hline Health literacy domain & Examples \\
\hline Reading and comprehension & Being able to recognize signs and symptoms of a heart attack or stroke \\
\hline \multirow[t]{4}{*}{ (Health literacy) } & Understanding systolic and diastolic blood pressure, and how to take or get a blood pressure reading \\
\hline & Being able to recognize symptoms of a high and low blood sugar \\
\hline & Understanding medications, including effects and side-effects \\
\hline & $\begin{array}{l}\text { Understanding nutrition factors, including calories; fat, saturated, mono-unsaturated, polyunsaturated, and } \\
\text { trans-fat; carbohydrates; sodium; vitamins and supplements }\end{array}$ \\
\hline \multirow[t]{5}{*}{ Numeracy } & Able to determine what range a blood pressure reading is in \\
\hline & Able to determine the range that a blood glucose is in \\
\hline & Can calculate insulin needs based on carbohydrate consumption and activity level \\
\hline & Can calculate dosage of medications \\
\hline & Can calculate sodium, calorie, fat, and carbohydrate intake \\
\hline \multirow[t]{4}{*}{ Navigation } & Able to fill medication prescriptions \\
\hline & Understanding when to go to the emergency department, when to dial 911, and when to call the doctor's office \\
\hline & Knowing how to select a physician, imaging center, or cardiac rehab program \\
\hline & $\begin{array}{l}\text { Able to determine of services, such as cardiac rehabilitation, or diabetes self-management are covered in the } \\
\text { health plan }\end{array}$ \\
\hline \multirow[t]{3}{*}{ Communication } & Knowing how to get information to the doctor, including the primary care physician \\
\hline & Knowing what information to share with the healthcare team, such as symptoms and medication side-effects \\
\hline & Knowing what questions to ask the healthcare team; and how to ask. \\
\hline \multirow[t]{5}{*}{ Decision making } & Able to select a cardiologist, surgeon, primary care physician \\
\hline & Make lifestyle choices, such as tobacco cessation, and dietary changes \\
\hline & Shared decision making on medication management \\
\hline & Shared decision regarding conservative therapy, $\mathrm{PCl}$, or surgery \\
\hline & Ability to validate information from medical and non-medical sources \\
\hline
\end{tabular}

This model can be implemented using either high or low touch solutions and either high or low-tech approaches. High touch solutions include the use of health coaches, or programs such as cardiac rehabilitation and diabetes self-management programs. Low touch solutions include print or text-based materials, such as a brochure or a static web page. High tech approaches might include the internet, mobile applications, or wearable devices. Low tech approaches face to face interactions with doctors, nurses, and other health care professionals. The key is to build a support system for patients, that teaches them the foundational skills necessary to master their health condition and then to implement this plan during the critical time when they are initially trying to figure out how to manage their illness. These skills include becoming more literate about healthcare issues relevant to their condition and being able to perform self-care. To be a successful model, it must be inclusive of all patients, regardless of their use of self-paced care devices (i.e., a mobile health app) or part of a program, (i.e. a cardiac rehabilitation). In addition, investments in educational and technological resources, and a commitment by healthcare professionals to educate patients will further increase the model's effectiveness

Of course, more research is needed to validate this chronic care model in a clinical setting studying the effect that this model has on the outcomes of patients with cardiovascular disease, hypertension, heart failure, lipoprotein disorders, atrial fibrillation, diabetes, and obesity. Also, better resources are required to help the patient evaluate the source of information, so they are not misled by solutions with unsubstantiated claims.

\section{References}

1. Benjamin EJ, Virani SS, Calloway CW, et al. on behalf of the American Heart Association Council on Epidemiology and Prevention Statistics Committee and Stroke Statistics Committee. Heart disease and stroke statistics-2018 update: A report from the American Heart Association. Circulation. 2018; 137: e67-e492.

2. Dunn P, Conard S. Chronic care model in research and practice. International Journal of Cardiology. 2018; 238: 295-296.

3. Dunn P, Milheim K. Enhancing informal patient education in nursing practice: A review of literature, Journal of Nursing Education and Practice. 2016; 7(2): 18.

4. Courtney M, Conard SE, Dunn P, et al. The Game of Health: An innovative lifestyle change program implemented in a family practice. Journal of the American Academy of Nurse Practitioners. 2011; 23: 289-297.

5. Dunn P, Conard S, Kirschner L. Playing the Game of Health: Best practices for health optimization program in a worksite setting, with case study of a real world example. Research in Health Science. 2017; 2. doi:10.22158/rhs.v2n1p41.

6. Smith SC, Benjamin EJ, Bonow RO, et al. AHA/ACCF secondary prevention and risk reduction therapy for patients with coronary and other atherosclerotic vascular disease: 2011 update: A guideline from the American Heart Association and the American College of Cardiology Foundation. Circulation. 2011; 124: 2458-2473.

7. Artinian NT, Fletcher GF, Mozaffarian D, et al. Interventions to promote physical activity and dietary lifestyle change for cardiovascular risk 
factor reduction in adults: A scientific statement from the American Heart Association. Circulation. 2010; 122: 406-441.

8. Magnani JW, Mujahid MS, Aronow HD, et al. on behalf of the American Heart Association Council on Epidemiology and Prevention, Council on Cardiovascular Disease in the Young, Council on Cardiovascular Stroke Nursing, Council on Peripheral Vascular Disease, Council on Quality of Care, and Outcomes Research and Stroke Council. Health literacy and cardiovascular disease: Fundamental relevance to primary and secondary prevention: A scientific statement from the American Heart Association. Circulation. 2018; 137: 00-00. DOI: 10.1161/CIR.0000000000000579.

9. Jordan JE, Buchbinder R, Osborne RH. Health literacy and communication: Conceptualizing health literacy from the patient perspective. Patient Education and Counseling. 2010; 79: 36-42.

10. Edwards M, Wood F, Davies M, et al. The development of health literacy in patients with a long-term health condition: the health literacy pathway model. BMC Public Health. 2012; 12: 130.

11. Rowland, G, Protheroe J, Winkley J, et al. A mismatch between population health literacy and the complexity of health information: An observational study. British Journal of General Practice. 65(635): e379-e386. DOI: https://doi.org/10.3399/bjgp15X685285.

12. Paasche-Orlow MK, Wolf MS. The causal pathways linking health literacy to health outcomes. American Journal of Health Behavior. 2007; 31: s19-s26.

13. Osborn CY, Paasche-Orlow MP, Cooper Bailey S, et al. The mechanisms linking health literacy to behavior and health status. American Journal of Health Behavior. 2011; 35: 118-128.

14. McNaughton CD, Collins SP, Kripalani S, et al. Low numeracy is associated with increased odds of 30-day emergency department or hospital recidivism for patients with acute heart failure, Circ Heart Fail. 2013; 6: 40-46.

15. Heijmans M, Waveijin G, Rademakers J, et al. communicative and critical health literacy of chronic disease patients and their importance for self-management. Patient Education and Counseling. 2015; 98(1): 41-48. DOI: http://dx.doi.org/10.1016/j.pec.2014.10.006.

16. Bellomo C. The effect of navigator intervention on continuity of care and patient satisfaction of patients with cancer. Journal of Navigation. 2014; 5: 6 .

17. Hess EP, Knoedler MA, Shah ND, et al. The chest pain choice decision aid: A randomized trial. Circulation: Cardiovascular quality and outcomes. 2012; 5: 251-259.

18. Allen LA, Stevenson LW, Grady KL, et al. Decision making in advanced heart failure: A scientific statement from the American Heart Association. Circulation. 2012; 125: 1928-1952.

19. Dunn P, Margaritis V, Anderson C. Understanding health literacy skills in patients with cardiovascular disease and diabetes. The Qualitative Report. 2017; 21(1): 3346. Retrieved from http://nsuworks.nova. edu/tqr/vol22/iss1/3.

20. Heijmans M, Waveijin G, Rademakers J, et al. Functional, communicative and critical health literacy of chronic disease patients and their importance for self-management. Patient Education and Counseling. 2015; 98(1): 41-48. DOI: http://dx.doi.org/10.1016/j. pec.2014.10.006.

21. Nutbeam D. The evolving concept of health literacy. Social Science and Medicine. 2008; 67: 2072-2078. 